\title{
Wayang Purwa dan Tantangan Teknologi Media Baru
}

\author{
Bedjo Riyanto \\ Jurusan Desain Komunikasi Visual, Fakultas Sastra dan Seni Rupa \\ Universitas Sebelas Maret Surakarta \\ Jurusan Desain Komunikasi Visual, Fakultas Seni dan Desain \\ Universitas Kristen Petra Surabaya \\ Email: bjriyantn@yahoo.com
}

\begin{abstract}
Abstrak
Seni pewayangan telah dikukuhkan oleh UNESCO sebagai Masterpiece of Oral and Intangible Heritage Humanity. Dan wayang kulit purwa sebagai salah satu jenis pertunjukan wayang muncul sebagai primadona yang paling hegemonic, mendapatkan perhatian sangat luas dari berbagai kalangan nasional maupun internasional, dan mampu bertahan hingga masa sekarang. Sehingga ada anggapan bahwa the real wayang adalah wayang kulit purwa. Globalisasi, komersialisasi, dan perkembangan teknologi komunikasi budaya populer sangat mempengaruhi perkembangan pertunjukan wayang kulit purwa ataupun wayang-wayang lainnya. Kemampuan adaptif yang kreatif sangatlah diperlukan dari segenap stake holders seni pewayangan agar dapat tetap lestari pada masa yang akan datang.
\end{abstract}

Kata kunci: Wayang kulit purwa, hegemoni, komersialisasi.

\begin{abstract}
The art of shadow puppets or wayang has been established as a Masterpiece of Oral and Intangible Heritage of Humanity by UNESCO. Leathermade shadow puppets or wayang kulit purwa as one of many wayang performances has been the most hegemonic, receiving much attention nationally as well as internationally until today. Therefore, there is an assumption that "the real" wayang is wayang kulit purwa. Globalization, commercialization, and the development of communication technology of popular culture influence greatly the advancement of wayang kulit purwa performances or even other wayang shows. Every stake holder of shadow puppet art truly needs the creative adaptive ability so that wayang can still be sustainable in the future.
\end{abstract}

Keywords: Wayang kulit purwa, leather shadow puppet, hegemony, commercialization.

\section{Pendahuluan}

Ketika Ki Hajar Dewantara menyatakan bahwa kebudayaan nasional merupakan kumpulan dari puncak-puncak kebudayaan daerah, salah satu puncak itu pastilah seni pertunjukan wayang. Wayang adalah ikon terpenting dari apa yang dibayangkan dan dibanggakan sebagai produk budaya adiluhung Jawa yang tentunya menjadi ikon terpenting pula bagi representasi ekspresi budaya nasional Indonesia sebab dalam peta demografis Indonesia, etnis Jawa menjadi etnis dominan yang paling hegemonik sebagai pemegang otoritas tafsir budaya dari Indonesia (sebuah komunitas anggitan yang tidak pernah selesai mencari format dan bentuknya sebagai suatu bangsa). Hegemoni seni pewayangan sebagai produk kreativitas budaya paling "dibya" dari keindahan, kecanggihan, dan keadiluhungan Jawa, pada sisi lainnya dapat berakibat terjadinya pemasungan, pembekuan, ataupun pengkerdilan secara involutif kebudayaan Jawa itu sendiri. Sebagai suatu paradok nyaris selama 11 abad masyarakat Jawa hidup, bangga, dan besar dengan wayang, tetapi nyaris mati, beku, dan habis dengan wayang karena nyaris tanpa satu pun produk kreativitas budaya yang mampu dihasilkan yang dapat menyamai atau menandingi kebesaran wayang. Kebanggaan semu itu terus dipelihara, dipertahankan, dilestarikan sejak masa kolonial sampai masa pasca kolonial tanpa ada suatu keberanian yang berarti untuk mendekonstruksi, mensubversi, merekreasi atau melakukan penjelajahan kreatif yang lebih mengakar dan mendalam untuk lepas dari kungkungan hegemoni wayang. Seolah-olah tanpa wayang kita 
menjadi masyarakat yang tuna budaya tanpa identitas dan kepribadian. Dan rupanya estafet pewarisan nilai-nilai wayang sebagai pusaka yang berdebu (karena masih terbatasnya keberanian untuk secara serius menafsirkan kembali, membedah kembali, melakukan penjelajahan penciptaan secara kreatif seni pewayangan dalam semangat kontemporer sesuai ruang waktu jaman si penafsirnya) mendapatkan legitimasi dan otoritas budaya global yang paling berpengaruh yaitu Unesco dengan menetapkannya sebagai "Masterpiece of oral and Intangible Heritage of Humanity" di tahun 2003. Pengukuhan ini semakin mengibarkan wayang dipuncak menara gading kegemilangannya sebagai pusaka budaya yang beku dan eksklusif.

Sosok wayang itu sendiri sebagai suatu produk kreatif yang mempunyai banyak jenis ragam cerita dan penampilan visual bonekanya yang ditafsirkan Unesco sebagai karya agung manusia di bumi ini, sering ditafsirkan secara sempit dan direduksi secara normatif hanya terbatas pada seni pertunjukan wayang kulit purwa atau pertunjukan wayang wong (orang) purwa yang bersumber pada tradisi kraton-kraton di Jawa Tengah yang klasik, filosofis, sakral, dan magis (pada dialog wayang dan jati diri bangsa yang disiarkan TVRI tanggal 7 Februari 2011 ketua umum Pepadi dan Senawangi kembali menegaskan wayang kulit purwa sebagai the real wayang yang adiluhung). Dalam interpretasi dan ekspetasi yang sangat normatif ini (normative expectation), seni pedalangan wayang kulit purwa yang bersumber pada tradisi klasik keraton-keraton di Jawa Tengah (Surakarta, Yogyakarta, Mangkunegaran dan Paku Alaman) dianggap seni pewayangan yang paling asli, murni, kesenian adiluhung Jawa yang sesungguhnya, halus, sakral, magis, agung, filosofis, yang menjadi kiblat kehidupan masyarakat Jawa. Cerita-cerita dalam wayang purwa bukan sekedar sebagai suatu fiksi tetapi sudah merasuk dalam ruang imajinasi masyarakat Jawa sebagai suatu realitas yang bersifat historis. Saking merasuknya rasa historisitas ini sampai-sampai silsilah genealogis rajaraja Mataram Baru (dari pendirinya Panembahan Senopati sampai Raja Keraton Surakarta atau Yogyakarta baik generasi Paku Buwana maupun Hamengku Buwana) bersumber dari tokoh fiktif dunia wayang yaitu Arjuna dan Parikesit putranya. Bahkan tokoh-tokoh politik penting era modern pasca kolonial baik dari Orde Lama maupun Orde Baru sering mengklaim dirinya pemegang wahyu bahkan titisan/reinkarnasi dari dewa-dewa dan ksatria wayang seperti Sri Kresna, Sri Rama, Arjuna, atau tokoh punakawan Semar. Padahal dalam evolusi panjang sejarah perjalanan seni pewayangan sejak disebutkannya dalam prasasti batu Raja Balitung sekitar tahun $907 \mathrm{AD}$ (sebutan wayang dengan mawayang) sampai dewasa ini menunjukkan adanya berbagai ragam versi, jenis, bentuk, boneka, garap rupa cerita, dan musik iringan dari wayang yang dimainkan oleh para dalang sebagai tokoh sentralnya (Claire Holt 2000). Diantaranya yang menonjol dalam catatan sejarahnya adalah:

1. Wayang Kulit Purwa, dengan boneka kulit pipih yang diukir/ditatah dan disungging dengan mengangkat repertoar cerita (pakem balungan) epos besar India Mahabharata dan Ramayana serta lakon-lakon carangan lokal jenius seperti Arjuna Wiwaha, Bina Suci, Arjuna Sasrabahu, dll.

2. Wayang Gedhog dengan boneka kulit yang ditatah dan disungging dengan repertoar cerita yang jalinan asmara Panji Asmara Bangun dan Dewi Candra Kirana dari kerajaan Jenggala dan Kediri.

3. Wayang Klithik atau Wayang Krucil dengan boneka dari kayu pipih dan tangan-tangan dari kulit yang ditatah dan disungging dengan repertoar cerita Damarwulan dan tokoh antagonis Minak Jinggo dari periode jaman Majapahit

4. Wayang Beber yang berupa gulungan kain yang dilukis dan disungging tokoh-tokoh wayang dengan repertoar cerita Joko Kembang Kuning dijaman Majapahit.

5. Wayang Madya, ciptaan Mangku Negara IV yang berdasarkan karya sastra pujangga besar Ranggawarsita "Pustaka Raja Madya" dengan kisah raja Jayabaya dari Mamenang Kediri yang termasyur dengan kitab ramalan jaman "Jangka Jayabaya" (yang bersifat prophetic atau ramalan kehidupan masa depan).

6. Wayang Golek dengan boneka dari kayu yang bersifat tiga dimensional dengan ditatah, diukir, dan disungging dengan repertoar cerita epos Mahabharata, Ramayana, serta legenda pahlawan Islam Amir Hamzah dengan punakawan-punakawan termasyurnya Umarmaya dan Umarmadi yang disebut sebagai wayang Menak.

7. Wayang Kuluk anggitan Sultan Hamengku Buwana V mengangkat cerita sejarah kasultanan Yogyakarta yang didirikan Pangeran Mangkubumi (Hamengku Buwana I).

8. Wayang Cina atau wayang Potehi yang mengangkat repentoar cerita legenda Sie Djin Koei (Hsueh Jen Kuei) seorang jenderal yang hidup pada masa kekaisaran Tang (Kaisar Toay Cung 627-649 AD).

9. Wayang Kancil dengan mengangkat cerita fabel kancil yang termasyur kreasi RM. Sayid dari Mangkunegaran. 
10. Wayang Suluh dengan cerita seputar revolusi kemerdekaan Republik Indonesia.

11. Wayang Wahyu dengan cerita kehidupan Yesus Kristus yang diciptakan oleh misi agama Katolik di Jawa Tengah.

Dan masih banyak lagi kreativitas-kreativitas lokal tentang wayang yang tidak tercatat dalam sejarah yang terserak dan terlupakan.

\section{Metode Penelitian}

Kajian ringkas ini menggunakan pendekatan metodologi sejarah poskolonial. Sebagaimana diulas oleh Dirks (2010) Indonesia pada dasarnya adalah negara bangsa produk kolonialisme sehingga persepsi dan produk budaya Indonesia banyak dikonstruksikan dan dibentuk oleh para elit kolonial, yang terus terekam dan terwariskan sebagai produk kebudayaan nasional. Tulisan ini sebagai sebuah analisis terhadap salah satu produk budaya bangsa yang terus bertahan sampai saat di tengah-tengah tantangan industri media komunikasi elektronik dan budaya popular.

\section{Pakem Ke(tidak)pakeman}

Aneka ragam kreasi wayang dalam rentang evolusi berabad-abad mengalami pasang dan surut perkembangannya dan yang paling menunjukkan keliatan, dan kemampuan adaptifnya untuk terus bertahan, bermetamorfosa dan akhimya menjadi kekuatan hegemoni budaya selama 11 abad adalah wayang kulit purwa. Posisi ini tidak begitu saja diperoleh, akan tetapi kebetulan sejarah dan dinamika politik kebudayaan dalam perjalanan kehidupan masyarakat Jawa banyak berperan terhadap kehadirannya sebagai sosok seni tradisional yang dominan dan paling berwibawa.

Mulai dari mitos cerita para wali penyebar agama Islam di Jawa (terutama Sunan Kalijaga sebagai budayawan Islam yang paling terkemuka) yang memanfaatkan seni wayang sebagai alat syiar Islamisasi Jawa sampai pada rekayasa budaya yang canggih dan sistematis dari kolaborasi elit bangsawan kraton di Vonstenlanden dengan para pejabat taal-ambtenaar (para pejabat dinas pendidikan dan kebudayaan pemerintah kolonial Hindia Belanda yaitu para filolog, indolog, atau intelektual orientalis Belanda dan Indo Belanda), menghasilkan format bentuk seni pakeliran wayang kulit purwa yang sering disebut sebagai pakem klasik adiluhung itu. Usaha kanonisasi kebudayaan adiluhung Jawa versi keraton yang dianggap klasik ini bukanlah semata-mata alasan murni kecintaannya terhadap multikulturalitas budaya Jawa yang sinkretik itu, melainkan adanya agenda-agenda politik kebudayaan dari elit pemerintahan kolonial Belanda atas menguatnya tekanan radikalisasi Islam sebagai kekuatan riil politik selain Belanda dan keraton masa itu. Perang Diponegoro atau perang Jawa (1825-1830) yang mengusung ideologi jihad atau perang sabil dengan simbol-simbol keislaman yang kental (dipimpin Pangeran Diponegoro yang menahbiskan dirinya sebagai ratu adil yang bergelar Sultan Ngabdulkamid Herucakra) serta kekerasan, dan kekejaman gerakan puritanisasi berdasarkan ideologi Islam radikal garis keras Wahabiah di Minangkabau dari kaum Paderi terhadap kaum Adat (dipimpin oleh ulama Tuanku Imam Bonjol) yang menelan korban jiwa ratusan ribu orang, benar-benar merupakan ancaman politik dan budaya bagi masyarakat sekuler maupun pemerintah Hindia Belanda. Pemaksaan penerapan syariah Islam dengan kekerasan dan peperangan merupakan ancaman serius bagi kehidupan budaya Jawa yang bersifat sinkretik dan multikultural dan juga menggoyahkan sendi-sendi ekuilibrium/keseimbangan, tertib kosmos, dan rust en orde yang menjadi rohnya. Dengan dukungan lembaga-lembaga Javanalogi (Java Instituut), KITLV (Koninkelijk Instituut Voor Taal-Land end Volkenkunde van Nederlandsch Indie) di abad 19, sampai lembaga Balai Pustaka (Commisie voor de Volkslectuur) diawal abad 20, bersama para maecenas budaya dan pujangga yang termasyur sebagai lima sekawan yaitu Mangku Negara IV, Pangeran Kusumadilaga (Keraton Kasunanan Surakarta), Ranggawarsita (Pujangga terakhir Keraton Surakarta), CF Winter dan Cohen Stuart, dikerjakan proyek besar penerjemahan sastra kawi Jawa kuno diantaranya wira carita Mahabharata, Ramayana, Kakawin Arjuna Wiwaha, Pustaka Raja Purwa serta Arjuna Sasrabahu kedalam bahasa Jawa baru (disebut sastra 'Jarwa') yang menjadi landasan penting bagi pakemisasi lakon-lakon pertunjukan wayang kulit purwa (pakem balungan). Usaha penyeragaman tafsir pertunjukan wayang kulit purwa dalam proyek pakemisasi secara lebih sistematis semakin kukuh dengan berdirinya sekolah pendidikan dalang Padhasuka (Pasinaon Dhalang ing Surakarta) atas perintah Susuhunan Paku Buwana X pada tahun 1923. Pada tahun 1925 kasultanan Yogyakarta mendirikan sekolah dalang sejenis sebagai reaksi dan respon dengan nama sekolah dalang Habirandha atas perintah Sultan Hamengku Buwana VIII (dengan dukungan Java Instituut). Tidak ketinggalan pada tahun 1931 Mangku Negara VII dari Pura Mangkunegaran mendirikan sekolah pedalangan dengan nama Pasinaon Dhalang ing Mangkunegaran (PDMN) 
(Sears, 1996; Groenendael, 1987; dan Margana, 2004).

Apa yang dibayangkan Pigeaud sebagai Renaisans Jawa (Golden Age Sastra Jawa) ini merupakan fondasi terpenting yang memungkinkan dilakukannya proyek pakemisasi seni pedalangan atau pertunjukan wayang kulit purwa dari tradisi lokal yang bersifat lisan ke dalam tradisi agung keraton yang berdasarkan teks sebagai babon pagelaran baku. Pakem disini dimaksudkan sebagai proyek penyeragaman pagelaran wayang kulit purwa yang meliputi penyajian cerita (pakem gancaran, balungan atau pedalangan), pakem berdasarkan pangadegan atau tata urutan cerita (pathet nem, pathet songo, dan pathet manyura menurut pakem Solo Yogya), serta pakem tata cara pengolahan dramatik vokal sang dalang sebagai pusat pertunjukan (seperti sulukan, janturan, pocapan, antawacana, ginem, sabet, dan lain-lain). Dengan sistem klasikal, kurikulum dan penggunaan buku-buku teks terjadi penggeseran yang sangat drastis dalam pengajaran pedalangan yang semula dilakukan secara lisan yang diwariskan secara turun temurun dilingkungan trah keluarga dalang dan bersifat isoteris. Terjadi proses masifikasi yang berarti seorang dalang tidak hanya lahir dari trah keluarga dalang seperti tradisi yang sudah terbentuk, melainkan dapat dilahirkan oleh sekolah-sekolah dengan metode modern. Sekolah pedalangan Habirandha mengembangkan buku pedoman baku pedalangan gagrag Yogyakarta yaitu Pedhalangan Ngayogyakarta Jilid I Gegaran Pamulangan Habirandha. Sekolah dalang Padhasuka menetapkan Serat Pustaka Raja Purwa karya pujangga Ranggawarsita sebagai kitab babon pakem lakon pedalangan Surakarta. Semasa pemerintahan Sultan Hamengku Buwana V juga telah memerintahkan pembakuan kitab babon pakem cerita pedalangan Purwakhanda. Klaim kesakralan dan aura magis religius seorang dalang mulai bergeser ke arah ketrampilan dan profesionalitasnya sebagai seorang entertainer atau aktor pertunjukkan. Uniknya usaha penyeragaman pakem lewat lembaga sekolah ini hanya terjadi dilingkungan kelas dan masa-masa belajarnya, selepas itu para alumnus sekolah-sekolah dalang ini kembali kepada mahzab, gaya, atau style kantung-kantung budaya lokal asalnya, dan itu melestarikan apa yang disebut sebagai pakemisasi ketidak pakeman dari seni pertunjukan wayang itu sendiri (paling tidak sampai sekarang masih dikenal otoritasotoritas tradisi yang melahirkan apa yang disebut sebagai pakem atau gaya khas pementasan wayang diantaranya gaya Surakarta, gaya Yogyakarta, gaya Banyumasan, gaya Jawa Timuran, gaya Pesisiran). Pasca kolonial obsesi dan semangat asas tunggal pakem tetap menjadi persoalan paradoksal yang tidak habis-habisnya diperdebatkan diantara para pelaku seni pedalangan, lembaga-lembaga pendidikan, dan otoritas politik kebudayaan sejak Orde Lama sampai Orde Baru (sebuah periode dimana seni pertunjukan wayang kulit purwa mengalami puncak kejayaan dan kebesarannya sebagai tontonan yang bersifat massal dan komersial). Pada saat negara bangsa yang modern berhasil diproklamisasikan sebagai sebuah republik yang bernama Indonesia, wayang atau seni pewayangan masih mempunyai kekuatan sebagai alat komunikasi politik yang cukup efektif baik ketika harus mewacanakan ideologi revolusi dimasa Orde Lama maupun alat sosialisasi dan mobilisasi ideologi pembangunan di masa Orde Baru. Dan para elit politik lewat aparatus organisasi pedalangan yang dibentuk seperti Ganasidi, Pepadi, Senawangi, Panakawan, ataupun lewat lembaga formal sekolah maupun perguruan tinggi seni seperti Konservatori, SMKI, ASKI, ISI dsb, merasa mempunyai kewajiban budaya untuk ikut nguriuri, melestarikan, bahkan mengkooptasi dan memproyekkan apa yang disebut sebagai asas tunggal pakem adiluhung sebagai acuan satusatunya seni pakeliran wayang. Kredonya adalah wayang sebagai tuntunan, tatanan, dan tontonan yang pada akhirnya lebih dominannya kepentingan politik dan ekonomi maka aspek hiburannya, komersialnya, atau tuntutan pasarnya disbandingkan kepentingan pelestarian nilai-nilai moral, tradisi, filosofi, atau religio magisnya sebagai tuntunan dan tatanan. Pada era Orde Baru dari elit puncaknya sang presiden, para menteri, para birokrat, sampai pada para saudagar/pengusaha kroni para birokrat merupakan para maecenas sponsor pertunjukan wayang kulit purwa yang fanatik dan bersemangat memanjakannya dengan fasilitas material, atau imbalan ekonomis yang luar biasa. Pementasan wayang kulit dengan dalang-dalang elit papan atas seperti Ki Anom Suroto, Ki Timbul Hadiprayitno, atau Ki Manteb Sudarsono menjadi simbol pengukuh status kelas sosial dan kepriyayian para elit orde baru.

Pagelaran wayang kulit menjadi semakin glamour, spektakuler, serba besar (gigantik) baik dari sisi Jumlah dalang, penonton, nilai kontrak bayaran, maupun atribut pementasannya itu sendiri (kelirnya berpuluh meter panjangnya, pesindennya puluhan dengan bintang tamu pelawak-pelawak terkenal atau pejabat-pejabat birokrat, dan gamelan pengiringnya dilengkapi dengan alat-alat instrumen musik modern seperti keyboard, drum-set, gitar elektrik, serta dimeriahkan oleh para penyanyi keroncong/campursari yang terkenal) (Umar Kayam, 2001). Seni pe- 
wayangan terutama wayang kulit purwa terus membayangi gerak perjalanan budaya bangsa Indonesia dengan segala obsesi, mimpi, kontroversi, bahkan hegemoni sebagai pusat yang paling sempurna (the exemplary of center) dari apa yang sering dinyatakan sebagai warisan adiluhung tradisi Jawa. Dan selama itu pula tarik ulur, kontroversi tentang apa yang dianggap pakem dan bukan pakem yang pada hakekatnya setiap usaha pakemisasi justru menuai ketidakpakeman, akan terus mewarnai hiruk pikuk gemebyarnya kelir dan blencong pagelaran wayang.

Dalam bayang-bayang kebesaran wayang kulit purwa yang dikukuhkan sebagai monumen keadiluhungan tradisi klasik Jawa, telah berserakan dalam kantung-kantung kecil kebudayaan, bentuk "wayang-wayang" yang dianggap "yang lain", liyan, "the others' yang terus mencoba bergulat dan menggeliat mempertahankan hidup dan eksistensinya sebagai kekuatan budaya tandingan (counter culture). Wayang-wayang dengan sajian cerita dan kemasan visual diluar mainstream adiluhung klasik seperti, wayang Adam Ma'rifat, wayang Pancasila, Wayang Dupara, Wayang Wahana, Wayang Jemblung, Wayang Gong Cangkem, Wayang Suket, Wayang Kardus, Wayang Topeng dan masih banyak yang tidak bisa disebutkan disini hampir dapat dipastikan belum banyak tersentuh oleh para intelektual pemerhati budaya dan pewayangan bahkan berada diluar sebutan seni pewayangan itu sendiri. Keberadaan mereka seolah diluar sistem, yang dilupakan, dibiarkan dalam keterasingan dan kesendiriannya. Demikian pula sajian "wayang yang lain" dengan format rupa dan media baru seperti cerita bergambar, komik strip, buku komik, brand/merk produk, etikel/label produk, animasi, iklan, multimedia dan sebagainya berada dalam posisi marginal, sub-ordinat, kelompok pinggiran, yang dicap tidak bermutu, picisan, murahan, rendahan, kacangan dan belum layak dianggap sebagai karya budaya atau kesenian.

\section{Tantangan dan Tafsir Media Baru}

Ketika pemerintah Hindia Belanda membuka keran liberalisasi perekonomian dan memicu industri modern di tanah jajahan pasca potitik Tanam Paksa tahun 1870-an maka arus modernisasi dan globalisasi budaya telah merambah dan tumbuh subur bersama lahirnya kota-kota modern diseluruh wilayah Nusantara. Dengan dukungan teknologi komunikasi dan industri komunikasi modern semacam pers, penerbitan, telepon, telegram, radio, kota-kota modern di seluruh wilayah Hindia Belanda menjadi ranah persemaian budaya kota (urban culture) yang bersifat instan dan populer. Awal abad 20, masyarakat Jawa masuk ke dalam lingkaran apa yang disebut sebagai Gutenberg Galaxy dan kota-kota modern yang lahir sebagai global village, dimana seluruh kekuatan media dan informasi menjadi sangat penting sebagai tulang punggung proses akselerasi menuju impian ke arah jaman baru yang modern dan maju (jaman kemajengan, kemajuan).

Proses refinement (penghalusan dan pencanggihan) dalam proyek harmonisasi dan pakemisasi wayang sebagai seni adiluhung klasik dalam kantung-kantung budaya eksklusif keraton dalam saat yang sama mendapatkan tantangan dan penggerusan yang hebat diluar tembok kesakralan dan kemagisannya. Terjadi proses masifikasi, desakralisasi, dekonstruksi, dan komodifikasi produk-produk budaya adiluhung Jawa termasuk tentunya sang ikon yaitu seni pewayangan menjadi produk budaya populer yang bersifat komersial, profan dan menghibur (sering disebut secara populer sebagai 'kitch" yaitu produk budaya kota yang dianggap dan diberi stigma, murahan, dan sekedar hiburan yang tidak bernilai). Gan Kam seorang pedagang impian (dream merchant) etnis Cina menjadi pelopor lahirnya kesenian kitch di Jawa atas ijin Sri Mangku Negara V mengkemas seni wayang wong yang semula merupakan seni ritual keraton Yogyakarta dan Mangkunegaran menjadi pertunjukan komersial yang disebut tonil wayang wong dengan panggung prosenium mirip opera Cina atau Opera Italia dengan pemain-pemain bekas wayang wong Istana Mangkunegaran ditambah dari masyarakat urnum, dengan penonton yang membeli tiket masuk. Kepeloporan Gan Kam telah melahirkan grup-grup tonil wayang wong yang legendaris sebagai monumen seni pertunjukan populer masyarakat Jawa seperti Ngesti Pandawa, Cipto Kawedar. atau Wayang Wong Sriwedari dengan maestro-maestro panggungnya yang sangat legendaris, seperti Ki Darso Sabdo, Ki Narto Sabdo, Sastro Dirun, Harjo Wugu dan generasi pasca kolonial Rusman, Surono dan Darsi.

Pasca revolusi kemerdekaan kehadiran industri penyiaran radio baik oleh lembaga pernerintah seperti Radio Republik Indonesia atau siaransiaran swasta niaga yang tumbuh menjamur sebagai media informasi dan hiburan kota, serta industri rekaman (recording) baik berupa piringan hitam, kaset, (atau yang paling mutakhir CD, VCD, atau MP3) yang dipelopori oleh perusahaan negara Lokananta, melahirkan format baru penyajian seni pewayangan yang bersifat auditif. Industri pita suara melahirkan gelombang trend wayang audio yang sangat populer di Jawa dengan dalang maestro seperti Ki Narto Sabdo, Ki Anom 
Suroto, Ki Timbul Hadiprayitno, atau Ki Hadi Sugito. Serial rekaman kaset atau CD dengan lakon Bharatayuda terutama episode Kresna Duta dan Pandawa Boyong dari Ki Narto Sabdo menjadi suatu karya masterpiece dari seni pedalangan auditif. Popularitas dan eksistensi seorang dalang sebagai pusat otoritas pertunjukan wayang ditentukan dan dipromosikan oleh institusi pengorbit seperti RRI atau perusahaan-perusahaan rekaman komersial produsernya. Kuantitas pendengar atau pembeli kaset menjadi salah satu tolok ukur kehebatan, kepiawaian, dan keempuan seorang dalang. Kapitalisme media dan industri penerbitan yang menjamur pada awal abad ke 20, juga memberikan peran yang sangat penting dalam proses desakralisasi dan komersialisasi seni pewayangan. Cerita pakem/wiracarita Mahabharata dan Ramayana serta lakon-lakon carangan klasik semacam Arjuna Wiwaha, Bima Ruci atau Arjuna Sasrabahu disajikan dalam kemasan teks buku-buku cerita dengan hiasan ilustrasi gambar-gambar wayang kulit purwa baik berbahasa pengantar Jawa maupun Melayu (menjadi bahasa Indonesia). Penerbit legendaris seperti Tan Koen Swie di kota Kediri dan Balai Pustaka menjadi maecenas-maecenas baru kelahiran komodifikasi cerita-cerita klasik adiluhung ini. Lahirlah genre baru dalam mengkemas seni pewayangan yang disebut sebagai komik wayang, embrionya dalam bentuk cerita ber-ilustrasi yang dimuat dalam majalah Kejawen (terbitan Balai Pustaka tahun 1935-1940) dalam rubrik khusus "Rembagipun Petruk dan Gareng". Dalam teks ini diceritakan keluarga punakawan itu terlibat persoalan dan membahas peristiwa-peristiwa sosial aktual yang terjadi di Hindia Belanda masa itu seperti Pasar Gambir, Semar Gareng Petruk ing dinten Riyadi; Jumenengan Ingkang Sinuhun Sultan Hamengku Buwana ke IX; Bab Pilem Terang Bulan; dll. Ilustrasinya dikerjakan oleh B. Margana yang menampil representasi visual hibrida yaitu figur Semar Gareng Petruk digambar realistik dengan mode busana jaman itu yaitu stelan jas (tuxedo), pantalon, surjan atau busana kejawen, pakaian tidur piyama, atau sekedar berkain sarung, akan tetapi raut wajahnya digambar dengan gaya visual stilistik dekoratif seperti wayang kulit purwa klasik. Tradisi visual yang dilahirkan B. Margana ini dilanjutkan oleh komikus Indri Sadono dari Semarang di era tahun 1960-an yang sangat populer dengan buku komik Dagelan Petruk Gareng.

Masa keemasan (golden age) komik wayang pasca kolonial terjadi ketika penerbit Keng Po di tahun 1954-1955-an menerbitkan lakon "Lahirnya Gatot katja" dan "Raden Palasara" karya komikus keturunan Cina John Lo. Disusul kemudian penerbit Melodi di Bandung menerbitkan karya-karya klasik komik Indonesia dari komikus-komikus legendaris seperti Ardisoma dan R.A. Kosasih. Kehadiran komik wayang sesuai dengan semangat revolusi masa itu, yaitu untuk membentuk karakter dan kepribadian bangsa (national charracter building) berdasarkan nilai-nilai adiluhung asli milik Bangsa Indonesia seperti sering disampaikan secara retoris oleh sang Proklamator Bung Karno dalam orasi-orasi politiknya.

Dengan mengangkat repertoar klasik wayang, wajah komik sebagai ikon budaya populer seni kitch yang dianggap picisan, murahan dan dekaden berhasil dipoles untuk tampil sebagai karya budaya dengan muatan sumber-sumber kebudayaan nasional untuk membentengi diri bangsa Indonesia dari pengaruh-pengaruh negatif kebudayaan asing kaum imperialis dan kaum neokolonialis yang dapat meracuni kepribadian kita yang luhur, halus, dan adiluhung. Selama periode keemasannya sampai dekade tahun 1970an, komikus Ardisoma menghasilkan serial "Wayang Purwa" sebanyak 22 jilid (masingmasing jilid 42 halaman), dan Lahirnya Sri Rama 2 jilid. Rekan sejawatnya yang bersama dengannya ditahbiskan sebagai legenda komik Indonesia RA Kosasih menciptakan Ramayana (4 jilid), Mahabharata (26 Jilid), Pendawa Seda (4 jilid), Bharatayudha (5 jilid), Parikesit (4 jilid), dan Udayana (4 jilid) yang kesemuanya ini menjadi karya klasik komik wayang Indonesia yang dianggap menjadi genre komik "asli Indonesia". Dan harus diakui generasi muda kota pasca kolonial baik masyarakat Jawa dan Indonesia pada umumnya mengenal cerita wayang yang dianggap sebagai pakem, babon, atau lakon baku secara sistematis dan komprehensif terutama epos-epos besar Hindu Budha Ramayana dan Mahabharata justru dari komik-komik 'kitch' wayang ini, bukan dari pagelaran wayang kulit purwa sang klasik adiluhung itu (Marcel Bonneff, 1998).

Kesadaran masyarakat Indonesia baru terhadap apa yang disebut seni pewayangan adalah kesadaran yang dibentuk oleh teks dan narasi Ardisoma atau RA Kosasih. Oleh karena visualisasi komik-komik wayang Ardisoma dan RA Kosasih banyak meminjam khasanah vocabulary visual wayang wong atau wayang golek Sunda, maka persepsi visual yang terbentuk dalam alam kesadaran kolektif masyarakat Indonesia terhadap wayang bukanlah representasi dekoratif stilistik wayang kulit purwa yang klasik itu, melainkan gambar-gambar berurutan (sequences) dan terjukstaposisi dalam panel-panel dan balon 
dialog komik itu. Wayang adalah komik RA Kosasih dan komik RA Kosasih adalah wayang itu sendiri. Meskipun ditahbiskan sebagai karya klasik dan menikmati popularitas dan kejayaan di era tahun 1960-1970 an, komik wayang tetap berposisi marginal, pinggiran, subordinat, yang lain, 'the others', yang tidak diakui, dibandingkan hegemoni pakeliran/pedalangan wayang kulit purwa sang ikon adiluhung monumen kebudayaan agung Jawa yang diangkat Unesco sebagai warisan karya agung umat manusia dunia itu.

\section{Penutup}

Cerita penutupnya seni pewayangan meskipun telah mendapatkan pengukuhan sebagai "Masterpiece of Oral and Intangible Heritage of Humanity" tidaklah serta merta tancep kayon menjadi cerita perjuangan yang final, melainkan justru merupakan awal tantangan untuk membuktikan kemampuannya untuk tetap lestari sepanjang jaman. Predikat yang diberikan oleh Unesco itu sewaktu-waktu dapat dicabut bila seni pewayangan tidak dapat melestarikan daya hidup dan perannya dalam kehidupan masyarakat pendukungnya. Tantangan industri media komunikasi elektronik dan budaya popular menjadi pertaruhan apakah para pemangku dan stake holders di dunia pewayangan mampu secara kreatif dan adaptif melakukan proses transformasi sehingga seni pewayangan tetap relevan dan berperan dalam arus perkembangan budaya global dimana nilai-nilai komersial dan popularitas menjadi faktor determinan dalam logika pasar dan dunia industri yang serba kompetitif dewasa ini. Perjuangan kreatif para seniman kontemporer penafsir wayang yang bebas liberal menurut kata hati, kejujuran, dan mengalirnya energi kreatif dalam ekperimentasi instalasi wayang kontemporer ala Picasso dari seniman kontemporer ter- kemuka Indonesia Heri Dono; eksperimen kreatif dalang teatrikal berpostur subur Slamet Gundono dengan Wayang Suket dekonstruksinya; Ki Jlitheng Suparman dengan wayang urban kampung sebelahnya; wayang rai wong karya dalang edan Ki Enthus Susmono; sampai generasi paling gres "Gundul" Herlambang Bayu Aji dengan eksperimen wayang Rajakaya-nya, masih bergerak terseok-seok dalam kantung-kantung kesenian kontemporer yang sangat terbatas baik pengaruh maupun kuantitas publik pendukungnya. Meskipun demikian keberanian mereka untuk menjebol sekat-sekat represi kea diluhungan lakon-lakon dan pakem-pakem pakeliran klasik yang murni dan asli berdasarkan tradisi, dengan penjelajahan kreatif yang tidak terbatas dalam menafsirkan kembali apa yang disebut sebagai pakem tradisi sesuai semangat kontemporer jamannya merupakan angin segar yang bertiup dari celah-celah kecil ruang besar kebudayaan yang penuh kegelapan kreativitas.

\section{Daftar Pustaka}

Bonneff, Marcel. (1988). Komik Indonesia, Jakarta: KPG (Gramedia).

Dirks Nicholas B. (2010). Kolonialisme dan Kebudayaan. Dalam Indonesia di Mata Poskolonialitas. Yogyakarta: Kanisius.

Groenendael, Victoria M.aara. (1987). Dalang Di Batik Wayang. Jakarta: Grafiti Pers.

Holt. Claire. (2000). Melacak Jejak Perkembangan Seni Di Indonesia, Bandung: MSPI.

Sears, Laurie J. (1996). Shadows of Empire Colonial Discourse and Javanese Tales. London: Duke University.

S. Margana, (2004). Pujangga Jawa dan Bayangbayang Kolonial, Yogyakarta: Pustaka Pelajar.

Umar Kayam (2001). Kelir Tanpa Batas, Yogyakarta: Pusat Studi Kebudayaan UGM. 